\title{
Common Perspectives on Tang Junyi's Thought
}

\section{Conservatism}

Tang's exilic perspective significantly deepened the "modern" turn in his interpretation of China's intellectual and social traditions. The continuation of traditions was no longer a matter of quasi-natural perpetuation, but based on efforts of renewal, rediscovery, re-appropriation, re-implementation and, most of all, discursive justification. As a private individual, Tang reacted to the exilic threat of a loss of traditional life forms by paying serious attention, apparently for the first time in his life, to the religious-ritual importance of holidays and festivities. He dealt with this topic quite exhaustively in his book The Spiritual Values of Chinese Culture, which he wrote shortly after arriving in Hong Kong. ${ }^{1}$ At home, he now worshipped ancestors, and he put up spirit tablets of Heaven and Earth (tian di 天地), his ancestors (zuzong 祖宗), and saints and worthies (sheng xian 聖賢). ${ }^{2}$

Still, Tang did not advocate an unconsidered, habitual perpetuation of traditional life. He never followed the traditionalist belief that the spheres of politics, economics, and science should be reined in and made directly accountable to a substantial set of values and virtues stemming from China's Confucian past. ${ }^{3}$ He consequently refrained from embracing the ideal of a thoroughly moralized "humanistic world" covering all social and cultural spheres of modern life. Even when strongly insisting on the need to uphold China's long-standing cultural traditions, he highlighted the aspect of reflexivity, i.e. the importance of a conscious re-appropriation of traditions from a transnational perspective. He thus clearly distinguished his brand of cultural conservatism from blatant traditionalism:

All these matters which have to do with [the notions] that "relatives should not forget their familial ties, nor old acquaintances their friendship," that one "does not forget an old agreement however far back it extends," that one should "not forget what [the old arrangements] were

1 See Chap. 9 of Tang's Zhongguo wenhua zhi jingshen jiazhi; see also Tang, Nianpu, p. 107.

2 Tang, Tang Junyi zhuanlüe, p. 63. Other rituals like the burning of paper money were not practiced at Tang's home (ibid.).

3 See e.g. the manifesto of 1958: Zhang, Zhongguo wenhua yu shijie, pp. 4-5, 18, 32-33, 35 . 
at first" and that one should "not lose one's roots," are wrongly deemed by contemporary psychologists, sociologists and specialists of historical culture as mere habits. [In fact,] these are [all issues of] conservation. I can sternly admonish the people of the world that these are certainly not mere habits, but indeed [issues] through which men truly achieve [their] being as humans, [and] through which I truly achieve myself-this is [at once] a factual and also normative principle. (...) The source of this conservation lies indeed in the immediate presence of man, [that is in the fact that he or she] has a strong and at the same time deep self-awareness about the past, the history, and the origins on which one's life rests and [in which it] is rooted. ${ }^{4}$

In labeling Tang's thought as conservative, as he did himself (see Chap. 4), it is necessary to differentiate between his culturally conservative position and a political conservatism, which he never advocated. He, indeed, wholeheartedly welcomed the revolution of 1911 and the founding of the republic in 1912. In fact, his modern Confucianism aimed to strengthen the republican order and to reinforce it by means of democratic-constitutional institutions. Tellingly, Tang also refrained from making political arguments against strands of rationalism, except for those totalistic tendencies which he identified with parts of the New Culture Movement. He criticized the latter for the false propagation of "science," which entailed a dangerously vague use of the label "unscientific" that served to depreciate other cultural values. ${ }^{5}$ Such criticism of New Culture rationalism, however, did not deter Tang from believing that individuals are able to lead their private and public lives in a reasonable and socially responsible way without a need to turn to political or religious authorities.

4 Tang, Shuo Zhonghua minzu zhi hua guo piaoling, p. 16. Tang quoted here passages from The Analects and the Book of Rites: 1) "that relations should not forget their relationship...." The Book of Rites II.2 section 3.24 (Legge, The Li Ki, Books I-X, p. 199); 2) "does not forget an old agreement ...." Lunyu XIV.13 (Legge, Confucian Analects, The Great Learning, The Doctrine of the Mean, The Works of Mencius, p. 280); the full passage reads: "The man, who in the view of gain thinks of righteousness; who in the view of danger is prepared to give up his life; and who does not forget an old agreement however far back it extends:- such a man may be reckoned a COMPLETE man."; 3) "not forgetting what they were at first:" The Book of Rites VIII.2 section 2.8 (Legge, The Li Ki, Books I-X, p. 408); the passage reads: "In ceremonial usages we should go back to the root of them (in the mind), and maintain the old (arrangements of them), not forgetting what they were at first."

5 On this criticism by Tang, see Huang, "Lun ruxue zhi zongjiao xing: yi Tang Junyi, Mou Zongsan xiansheng weili de sikao," p. 124. 
It is also significant that Tang's "conservative" standpoint embraces the anticipation of a future Chinese constitutional democracy, and hence neither defends the current state of affairs nor contemporary political institutions. Not even the events of 1949 caused Tang to contemplate a rapprochement with the GMD state, as Qian Mu 錢穆 (1895-1990), his fellow emigrant to Hong Kong, had done. A sound understanding of his conservatism requires that these peculiarities be taken seriously. Regarding typically conservative strains of thought, three stand out in Tang's Confucianism. First, there is the notion of an invariant human nature which is characterized by imperfection, seductiveness, and potentially insatiable desires. For example, in his analysis of the human desire for power Tang presumed that this desire was primordial and insatiable (see Chap. 7). The good in men thus becomes manifest only when they prevail over the subjectively evil and permanently exercise control over desires and instincts, thus reining in their unsociable side. Second, social, political, and economic inequality is interpreted as an inevitable consequence of the freedom of individuals in a society. Social hierarchies are hence to be seen as an appropriate expression of man's natural inequality. Thirdly, social deficiencies and malformations are said to be essentially the result of shortcomings in intellectual attitudes, spiritual outlooks, and distortions of cultural values. ${ }^{6}$

Another important topos of conservativism is absent from Tang's thought: The assumption that there exists a normative primacy of supra-individual orders (such as the state, traditions, the nation, the people, the community) over individuals. Tang refrained from making any claim that the individual obtains his or her correct standing in the world mostly through the workings of such orders. As he saw it, individuals do not actually need to subordinate themselves to such "greater" collectivities in order to overcome their egotism. On the contrary, Tang's civil theology is centered on the individual and posits the notion that the individual's self-fulfillment is the focal point of sound political judgment. Overall, then, Tang's conservatism aims to preserve the intellectual and cultural preconditions that will be needed to achieve the future modernization of China. Given that modernization is an ongoing process of normative, institutional, and functional differentiation, it is little surprising that Tang's "modernizing" conservativism puts forward a concept of Confucianism that anticipates such differentiation.

6 On these three topoi in "classical" German conservatism, see Lenk, Deutscher Konservatismus, pp. $37-38$ (on the first topos), pp. 66-67 (on the second), pp. 42-46 (on the third). 


\section{Neo-Confucianism}

Two monographs written by Tang during the 1950s offer a concise overview of his approach to traditional Chinese speculation and Confucian thought in general. These monographs are The Spiritual Values of Chinese Culture (Zhongguo wenhua zhi jingshen jiazhi) from 1953, and Cultural Consciousness and Moral Reason (Wenhua yishiyu daode lixing) from 1958. The Spiritual Values of Chinese Culture was written shortly after Tang's arrival in Hong Kong and is marked by an emphasis on early Chinese speculative thought, especially in the Book of Changes (Yijing 易經). ${ }^{7}$ Although Tang's interest in early Chinese speculation bears the imprint of neo-Confucian traditions of interpretation, he clearly attempted to move beyond neo-Confucianism. This can be seen prima facie from his categorization of neo-Confucian speculation under the "Western" label of xingshangxue 形上學—a loan word which was coined in Japan for the translation of the term "metaphysics."

What is more, Tang did not conduct research on neo-Confucianism with the traditionalist intention of adopting key concepts and ideas from neoConfucian thinkers as ready-made elements for contemporary philosophical use. He was convinced instead that the modern perspective required a thorough reinterpretation of neo-Confucian thought. Tang's own research in the field reached its peak with the volumes On the Sources of Chinese PhilosophyThe Sources of Teachings (Zhongguo zhexue yuan lun-yuan jiao pian 中國哲 學原論一原教篇, 1973) and On the Sources of Chinese Philosophy一The Sources of [Human] Nature (Zhongguo zhexue yuan lun-yuan xing pian 中國哲學 原論一原性篇, 1974). Here, and in a number of articles and essays about neoConfucianism, the focus is on notions of enlightenment and on the topic of self-cultivation, whereas less attention is paid to neo-Confucian writings on political issues, rituals, and social practice. ${ }^{9}$

7 Tang, Zhongguo wenhua zhi jingshen jiazhi, pp. 75-173. Tang emphasized the great importance of the Book of Changes for the development of speculative thought in China; see ibid., p. 92.

8 For example in: Tang, Zhexue gailun, Vol. 2, Chap. 19 (pp. 359ff.). Sanetō lists xing'ershangxue 形而上學 (identical with xingshangxue) as a Japanese loan word: Sanetō, Zhongguoren liuxue Riben shi, p. 232.

9 Cf. Lin, "Tang Junyi, Mou Zongsan de yangming houxue yanjiu," pp. 23-24. Tang concentrated on the following neo-Confucian figures: Shao Yong 邵雍 (1011-1077), Zhou Dunyi 周敦臨 (1017-1073), Zhang Zai 張載 (1020-1078), Cheng Yi 程弫 (1033-1107), Cheng Hao 程影 (1032-1085), Zhu Xi 朱喜 (1130-1200), Lu Jiuyuan, Wang Yangming, Liu Zongzhou 劉宗周 (1578-1645) as well as post-Wang Yangming thinkers and figures from the so-called 
Neo-Confucianism remained important for Tang's thought throughout the entire middle period of his intellectual development, as well as in his later work. At one point, he identified the Yijing and the Zhongyong 中庸 as particularly influential texts within the history of Confucian metaphysics. Yet the climax of neo-Confucianism was reached, according to Tang, in the work of Wang Yangming. ${ }^{10}$ The philosophy of Wang Yangming and his followers is conventionally referred to as the "study of the mind" (Xin xue 心學)—although this label was first introduced by their opponents. Wang Yangming himself called his brand of Confucianism "learning of the sage" (Sheng ren zhi xue 聖人之學), or "school of the sage" (Sheng men 聖門). ${ }^{11}$ The latter label is programmatic and clearly indicates the practical aims of Wang's teachings. It can be found in the Chuan xi lu 傳習錄, the seminal compilation for the study of Wang Yangming. The Chuan xi lu indeed influenced Tang's own philosophical project, which also pertains, to some degree, to the repetitive style of argumentation; the circular arrangement of topics, which are often discussed from different perspectives in different sections of a text; the didactic, if not to say homiletic, rhetoric of appeals; and the tendency to overwhelm readers by leading them again and again along similar lines of thought. ${ }^{12}$

Nevertheless, there are also fundamental differences between Wang's and Tang's philosophy, one of which concerns the former's aim to infuse speculative thought with practical import and describe a related way of living. Whereas Wang Yangming tried to do this in many sections of the Chuan xi lu and hence addressed his students in the role of a teacher or even leader of a sectarian group, Tang generally refrained from offering dogmatic prescriptions for individual and collective forms of life. It was his belief that everyone ultimately needed to follow his or her own path to the inner source of "sagehood." Moreover, it is noteworthy that when Tang discussed topics of self-cultivation,

Donglin movement (ibid.). In terms of academic impact, one can still agree with Chan Wing-tsit's statement from 1985 that Tang's (and Mou Zongsan's) seminal studies on neoConfucianism received only scarce attention in the United States (and in Europe, for that matter); see Chan, "Fifty Years of Chinese Philosophy Abroad," p. 11.

$10 \quad$ Tang, Zhexue gailun, Vol. 2, pp. 374, 378.

11 Wang, Chuan xi lu, pp. 88 (I.49), 178 (I.124), 295 (II.162). "Sheng men" is an old term that was used already by Ban Gu 班固 (32-92) in his Youtongfu 幽通賦 in reference to followers of Confucius (see Hanyu da cidian 漢語大詞典, Vol. 8, p. 669).

12 This view is in accordance with Thomas Metzger's assumption that Tang had a "BuddhistConfucian faith" which he "used to structure his whole philosophy" and that his writings were, thus, "fairly redundant, reflecting the religious impulse to return repeatedly to the same healing message:" see Metzger, A Cloud across the Pacific, p. 185. 
he mostly used newly coined terms like "spirit" (jingshen 精神) and "values" (jiazhi 價值). These terms lend themselves to such differentiating concepts as "cultural spirit," "religious spirit," "humanistic spirit," "philosophical spirit," "cultural values," "spiritual values," and "political values." They are consistent with modern differentiations into spheres of law (politics), morality (humanism, religion), science (philosophy), and aesthetics (culture). The implications of these normative, functional, and institutional differentiations with respect to concepts of culture and value would have been incomprehensible to Wang Yangming. Consequently, he would have missed the irony of using distinctly modern terms such as "jingshen" and "jiazhi" in order to affirm the continuity of China's cultural traditions and, simultaneously, to deflect the compulsory nature of modernity.

\section{Humanism and Religiosity}

The differences between Tang and pre-modern Confucian thinkers do not end here, however. Tang remained skeptical towards the political legacy of Confucianism throughout the middle period of his philosophical development. Given that his immersion in Confucian thought did not take place prior to the 1940 , it is likely that he was critical of political ideas from Confucian traditions right from the outset. ${ }^{13}$ Unfortunately, the intellectual circumstances that prompted Tang's turn to Confucianism, which occurred at around the time when he wrote the book The Establishment of the Moral Self (Daode ziwo zhi jianli, 1944), remain obscure. ${ }^{14} \mathrm{He}$ briefly stated in this regard:

... around 30, I took a liking to Western idealism. This was indeed not to be expected. From here, I again turned to reading Chinese Confucianism from the pre-Qin period, Neo-Confucianism and Buddhism, finally realizing [in what respect] pre-Qin Confucianism, neo-Confucianism and Buddhism for their part surpassed Western idealism. It was, however, not until the 37 th year of the Republic [= 1948; TF], that is around five or six

\footnotetext{
13 Liu Guoqiang applies a different periodization when concluding that Tang had turned to Confucianism at around the age of 30; see Liu, "Tang Junyi cong xin wu dao xin jing de sikao," p. 246. This assumption is difficult to substantiate.

14 However, in that book he also professed his general agreement with Hinayana-Buddhism as regards the view that the world itself was only a transitional state of existence and human life was bitter and, ultimately, illusionary; see Li et al., "Tang Junyi qi fo gui ru zhi yuanyin chutan," p. 21.
} 
years [ago], when writing the article about the original nature of religious consciousness, that I finally acknowledged the value of religions, and at the same time recognized the religious spirit within Confucianism. ${ }^{15}$

Prior to 1948, Tang had in fact only published eight articles on topics related to Confucianism, some of which were written when he was very young. ${ }^{16}$ When he studied philosophy, first at Peking University and then at Southeastern University (Dongnan Daxue 東南大學) in Nanjing, he had taken an outspokenly critical stance towards contemporary Confucian thinkers like Liang Shuming, Xiong Shili, or Fang Dongmei 方東美 (Thomé H. Fang; 1899-1977), whom he had personally met in classrooms and at lectures. ${ }^{17}$ Of course, this does not preclude the possibility that he absorbed ideas at this formative stage of his intellectual development that would contribute to his immersion in Confucian thought later in his life. Although he did not subscribe to any particular school or philosopher at that time, it seems likely that those intellectual currents of the 1920 s which advocated a renewed interest in China's Confucian past and a reinterpretation of Confucianism as a humanistic tradition had made an impression. Southeastern University was a hotbed for intellectuals who were critical of the New Culture Movement's totalistic tendencies. Some of them gained prominence by participating in a loose network of scholars who published essays and translations of Western scholarship in the journal Xueheng (學衡; The Critical Review), founded in 1922. Contributors include the literary scholar and philologist Wu Mi 吴宓 (1894-1978), the literary scholar Mei Guangdi 梅光迪 (1890-1945), the biologist and educator Hu Xiansu

15 Tang, Renwen jingshen zhi chongjian, p. 571 (this passage is from Tang's account "Wo duiyu zhexue yu zongjiao zhe jueze 我對於哲學與宗教之抉擇”). Tang's own reference to his article on the religious consciousness is unclear. According to the Chronological Table of [Tang Junyi's] Writings, he published an article entitled "On the Original Religious Faith and Confucianism in China" in the March 1948 issue of the journal Ideal, History and Culture (Lixiang, Lishiyu Wenhua 理想, 歷史與文化). In 1950, an article about the "original nature of religious consciousness" appeared in the May issue of the journal Ideal and Culture (Lixiang yu Wenhua); see Tang, Zhushu nianbiao, pp. 15, 17.

16 See Tang, Zhushu nianbiao, pp. $3^{-15}$. Tang discussed in these articles the Xunzi, the Mencius, Confucius and Goethe, the Book of Changes and the Doctrine of the Mean, Zhu $\mathrm{Xi}$, and neo-Confucianism in general.

17 Tang attended lectures and courses taught by Xiong Shili, Fang Dongmei, Tang Yongtong 湯用粀 (1893-1964) and others while studying philosophy as a major and literature as a minor at Southeastern University. Nevertheless, as Tang Duanzheng put it in the Nianpu, he was still convinced that the teachings of the ancient Chinese sages were of little if any use to the contemporary world; see Tang, Nianpu, pp. 21, 23-24. 
胡先㵲 (1894-1968), the philosopher Liu Boming 劉伯明 (1887-1923), and the historians and philologists Liu Yizheng 柳詒徵 (1880-1956), Chen Yinke 陳寅 恪 (1890-1969), and Tang Yongtong.

None of these scholars figure prominently in Tang's work, nor does the American classical scholar and Harvard professor of French literature Irving Babitt (1865-1933), who was the academic teacher of Wu Mi and the central figure of the so-called New Humanism in America. All the same, it is likely that ideas and positions from Xueheng and its introduction of Babbitt's "New Humanism" to a Chinese readership helped stimulate the common interest in a modern renewal of Confucianism. The influence of Xueheng intellectuals on modern Confucianism is much more obvious with regard to the selection of topics and a generally critical outlook on the contemporary world than particular analyses and interpretations of scholarly works. There was, above all, a cosmopolitan culture, purportedly on the rise worldwide, that was fostered by Western and Eastern strands of humanism and also included religious traditions. ${ }^{18}$ This burgeoning humanistic culture was expected to counteract some of the worst side effects of social modernity. The latter were addressed under such topics as rampant materialism, consumerism and urbanization, the decay of the "republican spirit," the upsurge of a misguided scientism in education and scholarship, and the triumph of Marxism and communism. Besides, Xueheng joined in Babbitt's call for an "aristocracy of character and intelligence." Its members were to receive their formation in a broadly humanistic, liberal and moral education that predetermined them to take up political

18 See Liu, Translingual Practice. Literature, National Culture, and Translated ModernityChina 19oo-1937, pp. 248, 251, 432. Lydia H. Liu contends that "the idea of new Confucianism was first imported from the West" (p. 432, note 41) and refers to Hu Xiansu's translation of Irving Babbitt's "Humanistic Education in China and the West," which was published in Xueheng in 1922 (see Bai, "Bai Bide Zhong Xi renwen jiaoyu shuo"). The fact that the term "renwen 人文" ("humanistic"), which was to become a key concept in modern Confucianism, figures prominently in Hu's translation is indeed remarkable (see also Liu, ibid., p. 251). Even though it is problematic to pinpoint, as Liu does, the formation of an intellectual current which is as comprehensive in scope and intrinsically diverse as modern Confucianism, Liu's contention is relevant for a historically sound understanding of how the initial interest in reinterpreting Confucian traditions as "humanistic" took shape. The complexity of this formation in terms of intellectual history can be highlighted by the fact that Hu translated Babbitt's call for a "new" Confucian movement with the term "xin Kong jiao zhi yundong 新孔教之運動” (see Bai, “Bai Bide Zhong Xi renwen jiaoyu shuo," p. 48). Years later, Tang and his fellow advocates of modern Confucianism were careful to reject the invocation of a renewed Confucianism as "Kong jiao," a term that was closely linked to earlier attempts to establish Confucianism as a state religion. 
and educational duties and thus to contribute to the sound foundation of the republican community in civic virtues and values. ${ }^{19}$

It is along this spectrum of a critique of modernity that the vestiges of Xueheng ideas can be found in Tang's philosophy. The correlations, however, do not cover the whole breadth of Tang's reflections on modernity, neither in terms of the range of topics, nor with regard to the analytical depth. Indeed, it is hardly surprising that Tang departed in many respects from the earlier critics of modernity given that he developed the main body of his philosophical work in exile after 1949. This was not only more than three decades after the Xueheng-discourse was at its peak, but also in a vastly different historical context. For one, Tang was no longer concerned with the problems of political mass participation by illiterates. He also did not subscribe to the idea of a political elite serving as role models for citizens or as paragons of the republican spirit. Nonetheless, he still emphatically referred to the need to retrieve a "classical spirit" in modern society to counter rampant materialism. He also described "ideal politicians" as if they belonged to an "aristocracy of character and intelligence" within an otherwise egalitarian society (see Chap. 11). Notwithstanding these prima facie affinities with Xueheng, there is no evidence that Tang ever shared the conviction that scholar-poets or cultural heroes could actually shape modern society. Nor did he endorse the idea of obtaining politically effective values from classical scholarship and literature. Tang ultimately conceived of the interrelations between the humanistic and the political realm in a much more complex manner. For example, he subscribed, among other things, to the notion that the humanistic sphere in modern societies should be relieved from the burden to produce an immediate political effect, whether in the form of political values and norms or in politically exemplary personalities (see Chap. 9).

Clearly, Tang's account that his intellectual development was characterized by the fact that his interest in Western idealism predated his immersion in Confucianism does not convey the full picture. He had been attracted to a broad range of intellectual currents before he thoroughly familiarized himself with Confucian thought. Apart from German idealist philosophy, New Humanism and readings into the Western canon of classical philosophy, he had read works of Marx and Lenin, Bertrand Russell, Henri Bergson, Alfred North Whitehead, and others. At one point, he also studied contemporary

19 For an excellent overview of the intellectual agenda of Xueheng-intellectuals like Wu Mi and Liu Boming, see Hon, "From Babbitt to 'Bai Bide': Interpretations of New Humanism in Xueheng," pp. 255-256, 259, 261; see also Schneider, "National Essence and the New Intelligentsia," pp. $73^{-75}$. 
scientific theory. These readings were probably stimulated by his intellectual development at Peking University, where he was enrolled from 1925 to 1927. While there, he attended lectures and courses taught by Liang Qichao, Zhang Dongsun, Jin Yuelin 金岳霖 (1895-1984), Hu Shi 胡適 (1891-1962), and others. ${ }^{20}$

Tang's following turn to Confucianism bears the imprint of a religious conversion that befitted his strong sense of mission and messianism (an aspect described in more detail in Chap.4). By adopting his Confucian agenda with these proclivities, Tang entered the ranks of thinkers who, since the Song Dynasty, had professed experiencing a sort of personal enlightenment in turning to Confucianism (mostly by renouncing Buddhism). In the late 19th and early 2oth century, Kang Youwei 康有為 $\left(185^{8-1927)}\right.$ and Liang Shuming, for instance, displayed a strong world-saving missionary sense in their accounts of their Confucian conversion. As for Tang, he stated that when he experienced his own personal epiphany at the age of 26 , he did not believe in Buddhism. ${ }^{21}$ That said, he was almost certainly familiar with Yogācāra Buddhism at that time, especially as his father was deeply impressed by the Buddhist scholar Ouyang Jingwu. ${ }^{22}$

In light of his familiarity with Buddhism, it is less surprising that Tang took an immediate interest in the religious dimension of Confucianism. When exploring the possibilities of reinterpreting Confucianism as a form of "religiosity," he tapped into neo-Confucian currents by applying a terminological strategy of introducing new terms to determine the meaning of traditional notions. References to the notion of "Heaven," for example, are linked with the philosophical term for the "absolute" (juedui 絕對), which is not found in Chinese texts predating the 2oth century. Still, Tang's approach to Confucian religiosity drew on neo-Confucianism, including notions of sagehood and speculation

20 On Tang's readings of Western philosophy, see Tang, Shengming cunzai yu xinling jingjie, Vol. 24, pp. 470-473; Tang, Nianpu, pp. 18, 23-24. Thomas Metzger states that, prior to his interest in German idealism, Tang had criticized it from the perspective of empiricist theory; see Metzger, Escape From Predicament. Neo-Confucianism and China's Evolving Political Culture, p. 244). On Tang's attendance of classes and lectures held by Liang Qichao, Hu Shi, Zhang Dongsun, Jin Yuelin, and others, see Tang, Nianpu, pp. 16, 18-19.

Tang, Shengming cunzai yu xinling jingjie, Vol. 24, p. 470. Tang's account of his epiphany in Shengming cunzai yu xinling jingjie may suggest that he experienced some sort of "Confucian" awakening. However, he was at that time not deeply immersed in Confucian thought.

22 Ibid., p. 480. Tang had received an early education by his parents and was instructed up to the age of 10 by his father, who read to him the Dao de jing 道德經, poetry from the Tang period, and other texts outside of the Confucian canon; see Tang, Nianpu, pp. 5-7. 
about the relation between man and "Heaven." Rodney L. Taylor highlights "the religious character of the goal of sagehood ... as an experience of unity of self with Heaven. This provides a basis for the soteriological or transformational character of learning and self-cultivation." ${ }^{23}$ In reference to Tang's thought, one can agree with Taylor's conclusion that " $\mathrm{r}]$ eligion thus involves a perception of, knowledge of, or insight into, that which constitutes the Absolute and, in addition, the ability to provide a means for the individual to engage in an ultimate transformation toward that which is regarded as the Absolute, the fulfillment of the relationship between the individual and the Absolute."24

\section{Dogmatism}

Whereas Tang's turn to the religious dimension of Confucianism is affirmative in character, a different picture emerges with regard to his approach to Confucian traditions of political thought. In the early 1950s, his appraisal was generally still positive, for example in The Spiritual Values of Chinese Culture. ${ }^{25}$ It then turned negative in his writings from the mid-1950s onwards, as he identified a number of problematic issues in Confucian political thought and practice. While conceding that Confucianism had produced some ideational and mental "roots" of democratic government, he emphasized that neither democratic practices nor constitutional government or the rule of law had evolved out of Confucian political traditions. Even worse, the political heritage of Confucianism as exemplified by Yuan Shikai and, later on, the GMD of the post1949 period hardly appeared to have been immune to the lure of dogmatism and political authoritarianism. The question at hand, therefore, was whether the political traditions of Confucianism could in any way contribute to the future formation of a democratic Chinese nation-state. Tang's critical reflection on this question was also motivated by his interest in the problem of evil

23 Taylor, The Way of Heaven. An Introduction to the Confucian Religious Life, p. 7. Taylor raises another point which is relevant for Tang's concept of religiosity, namely that "[n]otions of the Absolute within religion can appear in different forms-transcendent or immanent, theistic or monistic." See Taylor, "The Religious Character of the Confucian Tradition," p. 82. With respect to the identification of sagehood as a "religious goal," Taylor affirms that this is "a question left largely to the interpretation of the individual scholar." See Taylor, "The Study of Confucianism as a Religious Tradition: Notes on Some Recent Publications," p. 149.

24 Taylor, "The Religious Character of the Confucian Tradition," p. 84.

25 See e.g. Tang, Zhongguo wenhua zhi jingshen jiazhi, p. $77^{2}$. 
and power in the political realm - an interest that was perhaps aroused less by his philosophical readings than close observation of particularly violent methods of political rule in the PRC since the 1950s (see Chap. 9 and 12). It seems that the aim of coming to terms with political reality necessitated a reconceptualization of politics and power, and yet traditional Confucian thought had little to offer in this regard. Consequently, Tang's political philosophy greatly differs from pre-modern Confucian political thought due to its sharp conceptual distinction between politics and ethics and its theory of power. Mou Zongsan is perhaps the only other philosopher of modern Confucianism to follow a similar path in criticizing traditional notions of a politico-ethical continuum.

Current discussions of Tang's ideas, however, are often burdened by inadequate depictions of his philosophy as a thoroughly traditionalist brand of Confucianism or as a lofty metaphysical effort prone to lead to an estrangement of philosophy from the historical world. Yu Yingshi 余英時, for example, assumes that Tang, like Mou Zongsan and Xu Fuguan, was a follower of Xiong Shili's philosophy and thus belonged to a philosophical school which produced arbitrary ("subjectivist"), quasi-religious interpretations, or even distortions, of Confucianism. These interpretations, if we are to follow Yu's critique, rest on a sectarian-like "arrogance of liang $z h$ " that in effect endorses a dangerous irrationalizing of social and political life. Yu wants to counter such aberrations, while also emphatically excluding his teacher Qian Mu from any culpability in this regard. He thus offers a reinterpretation of Confucianism that contents itself with questions pertaining to the individual's everyday life, rather than clinging to vain hopes of inscribing Confucianism into political institutions. ${ }^{26}$ But, Tang was not a "disciple" of Xiong, at least not in the traditional sense of a masterdisciple relationship. He also would not have welcomed the establishment of a sectarian Confucian school, let alone the founding of such a school within political or religious institutions. Yu is certainly correct to raise the issue of irrationalizing tendencies in Tang's (and Mou Zongsan's) Confucian philosophy. Yet contrary to what Yu observes, the problem is not with a hypostasis of intuitive enlightenment (through liang zhi) at the expense of discursive forms of practical reason. After all, Tang did not simply negate reason with an irrational belief in intuition. He rather attempted to link practical reason to the spiritual realm of liang zhi.

The issues $\mathrm{Yu}$ addressed were also raised by contemporary critics of Tang from the Mainland. However, their criticism has been challenged. In a

26 Yu, Xiandai ruxue lun, pp. 125 (on Xiong Shili as a founding figure), 155 (on the critique of liang zhi-thought), 171-179 (on the reinterpretation of Confucianism). 
trenchant refutation, Lee Ming-huei rejects Liu Xiao's generalizing assessment that modern Confucian philosophers systematically confounded politics and ethics, as well as the subjective will and objective social relations. Liu's misjudgement seems to be due, as Lee points out, to a lack of familiarity with the writings of Tang Junyi and Mou Zongsan. ${ }^{27}$ Like Liu Xiao, Jiang Qing depicts modern Confucianism or what he calls in English "mind Confucianism" (xinxing ruxue 心性儒學) as a philosophy that deals exclusively with questions of "life" (shengming 生命), ethics, and metaphysics, while completely neglecting political aspects. ${ }^{28}$ Similar criticism had been levelled earlier against modern Confucianism by Yin Haiguang 殷海光, Zhang Foquan 張佛泉, Wei Zhengtong 韋政通, Lin Yusheng 林毓生 and Zhang Hao 張䫝. They all deplored that modern Confucianism was too abstract in thought, too "metaphysical," and unduly inclined to the belief that complex problems of modern societies could be solved altogether in the sphere of "culture."29 One may also include here Lao Sze-kwang 勞思光, who wrote an essay suggesting that a "Chinese cultural movement" needed a "fundamental" concept to overcome the "deficiencies of traditional culture." Lao clearly implied that Tang's modern Confucianism lacked such a concept and was therefore essentially apologetic. ${ }^{30}$

Wei Zhengtong and Lin Yusheng, both of whom had been close intellectually to Yin Haiguang for some time, were particularly critical of Tang's allegedly apologetic stance towards Chinese traditional culture, and, most of all,

27 See Li Minghui (Lee Ming-huei), Rujia shiye xia de zhengzhi sixiang, pp. 271-272; for Liu Xiao's critique, see Liu, Xiandai xin rujia zhengzhi zhexue, p. 328.

28 Jiang, Zhengzhi ruxue, pp. 20-23, 25. Jiang Qing reiterates this statement about "mind Confucianism" - a label that includes the philosophy of Tang Junyi as well as Mou Zongsan - when identifying as its "main concern... the existential life of human individuals and their minds, rather than socio-political institutions." See Jiang, "From Mind Confucianism to Political Confucianism," p. 18. Perhaps such distortions are not just a matter of limitations in the reception of Tang's philosophy, but rather a case of keeping silent about a critical strand of Confucian political thought that does not fit certain political agendas.

29 For an overview of this criticism, see Chen, “Tang Junyi de ziyou renquan guannian," p. 46.

30 Lao's essay appeared shortly after Tang's death in 1978, when close to one hundred commemorative texts were published in Hong Kong and Taiwan; see Lao Siguang (Lao Sze-kwang), "Chengbai zhi wai yu chengbai zhi jian-yi Tang Junyi xiansheng bing tan 'Zhongguo wenhua' yundong," p. 78; Fang Keli agrees with Lao's assumption and maintains that it pinpoints the crucial reason why the "movement" of modern Confucianism did not succeed; see Fang, Xiandai xin rujia xue an, Vol. 1, p. 37. 
Confucianism. ${ }^{31}$ In an extensive academic interview on Tang Junyi from May 1978, Wei suggested that Tang had never abandoned "traditional values" and had simply neglected the need to comprehensively reflect on modernity. Tang was allegedly content to dissect some weaknesses in modern man and consequently never directly dealt with modernity, either psychologically or intellectually. In the same vein, Wei assumed that in the context of the antiConfucian tendencies from the Republican period, there were personal and psychological factors at work which fueled Tang's "missionary" zeal to propagate Confucianism. Wei even mockingly referred to Tang as the "shepherd of the Confucians," who was driven by strong religious "feelings." ${ }^{32}$ Lin Yusheng, too, found fault with the alleged absence in Tang's work of a critical approach to "China's traditional culture" and ascribed this deficiency to Tang's supposed assumption that "all the things past" were "reasonable." This has the familiar ring of similar criticisms of Hegelian philosophy, and Lin indeed depicts Tang's philosophy as an ill-conceived, even "chaotic" mélange of Huayan Buddhism and Hegel's philosophy of history. To make things worse, Tang ostensibly failed to thoroughly criticize Hegel's philosophy for its complex but, according to Lin, close connection to the later rise of fascism. Tang is also said to have had a "state of mind" that kept him from voicing profound criticism of "traditional Chinese culture." As a consequence, instead of adequately reacting to the problem of intertwining a complex cultural tradition (i.e. Confucianism) with an equally complex modernity, Tang merely resorted to an escapist attitude. ${ }^{33}$

Both Wei Zhengtong and Lin Yusheng argue at times ad hominem and, as Lin's generalizing remark on Hegelian philosophy and fascism exemplifies, they do not shy away from polemics. Still, the problem with their criticisms is

31 In his account of his own intellectual background and development, Wei refers to Lin Yusheng as a "disciple" of Yin Haiguang; see Wei, Sixiang de tanxian, p. 93. Wei also recounts how he and Yin Haiguang had first met in Taibei in May 1965 when Yin invited him to deliver a lecture at National Taiwan University. Thereafter, Wei and Yin met regularly and remained in close intellectual exchange until Yin's death in 1969; ibid., p. 74. According to Wei, Yin Haiguang had made "new Confucianism" (xin rujia 新儒家) his prime intellectual foe. Wei and Yin agreed that modern Confucianism should not be considered representative of the Confucian tradition; see Wei, Chuantong de gengxin, pp. 270-271.

Wei, Chuantong de gengxin, pp. 205-207, 221-227.

33 Lin, Sixiang yu renwu, pp. 413-416 (reprinted from Zhongguo luntan 中國論壇, Vol. 15, No. 1 [Oct. 10, 1982], pp. 21-24.) Li Zhifu's judgment is diametrically opposed: He praises Tang for his apologetic attitude towards China's national culture and the thought of Confucius; see Li, "Tang Junyi sixiang zhi minzu wenhua guan ji qi aiguozhuyi jingshen zhi tantao," pp. 221, 227. 
not that they were completely off the mark. As discussed in Chapter 4, there are indeed parts of Tang's work where he was prone to a highly declamatory writing style. He also occasionally shows a tendency to cling to China's spiritual culture that has a chauvinistic ring to it. Yet his thought is ambiguous in this regard. There is in fact a strong tendency in this work to criticize the political tradition of Confucianism for its alleged dogmatism and its failure to clearly distinguish between the spheres of politics and ethics. Overall, the above criticism of Tang's supposed apologetic approach to China's intellectual traditions does not withstand scrutiny. What is more, the critics convey a rather one-sided view of Tang Junyi's reflections on modernity. While he may certainly be criticized for making particular assumptions, it simply does not do justice to Tang's philosophical endeavor to say that he never engaged in a comprehensive reflection on modernity. It should be noted here that Lin Yusheng himself remarked that he had not engaged in "systematic research" on the works of modern Confucian thinkers. ${ }^{34}$ It is also ultimately not clear which of the works by Tang formed the basis of Wei Zhengtong's and Lin Yusheng's interpretations. ${ }^{35}$

A more extensive reading into Tang's work would have shown that Tang was keenly aware of the ideological dangers lurking around an apologetic approach to Confucianism under modern conditions. Tang warned against the reduction of Confucianism to a "profane utilitarianism and positivism,"36 for it could then be easily turned into a means to bolster political dogmatism. His restraint in presenting ready-made "Confucianized" political solutions when it came to problems occurring in social modernity was due to this anti-dogmatic outlook. Not only was he highly critical of Confucian political traditions in general, but he also took issue with a self-contained intellectual attitude in which conventions and traditions are upheld without prior reflection. He even contended that such an attitude might represent a breaking point for totalitarianism:

34 Lin, Sixiangyu renwu, p. 411.

35 Lin Yusheng's detailed and insightful analysis of the manifesto of $195^{8}$ must hence be considered to be exceptional. Lin takes issue with the manifesto's assumption that there are intellectual resources in Confucianism (among them the notion of moral subjectivity) that initiate by necessity the formation of a liberal democracy in Chinese modernity. Lin also critically notes the modern Confucians' conviction that the triggers of historical development were in essence ideational forces. He calls this a "cultural-intellectualistic approach," which is also observable in May Fourth anti-traditionalism; Lin, Zhengzhi zhixu yu duoyuan shehui, pp. 341-345.

36 Tang, Zhongguo renwen jingshen zhi fazhan, p. 370. The critics of such profane Confucianism would be compelled, according to Tang, to take up the unworldly role of monks; ibid., pp. 366-367. 
Finally, [as regards whether] I comply with my common perceptions which naturally evolved, or [whether I] think according to prevalent perceptions, or follow what I discovered in my own true cognition (zhen zhi 真知), this is what we must decide first. If we think solely by complying with our own, [naturally evolved] perceptions or the prevalent perceptions, then... [we] are at any time prone to be misled by all [kinds] of political, religious, and social propaganda... People of this kind are most suited as subalterns and slaves in a totalitarian system. (...) In fact, the great majority of people [remain] in everyday life most of the time in a passive state of mind, lastingly tied down by [such] perceptions. This is indeed a hopeless situation. However, the beginning of the decision to think should [be marked by] the resolution to strive for transcending this [passive] state of mind ... and to strive, in all respects, to follow what [we] have reached by [our] own true cognition. (...) At different times, men can pursue various kinds of true cognition. According to their respective dispositions, they are likely to pay special attention to pursue a particular kind of true cognition throughout their lives. In so doing, they turn into different types of entrepreneurs, scholars, or exponents of religions. [But] no matter what kind of true cognition they are striving for, autonomous and sovereign judgments are equally indispensable. ${ }^{37}$

Tang's warning against misinterpretations of Confucianism might also have been readily applied to the GMD's efforts at a grassroots level to foster Confucian values among the Taiwanese population during its campaigns for the "Revival of Chinese Culture" in the late 196os and for a "Cultural Reconstruction (wenhua jianshe 文化建設)" in the 1970s. In terms of civic consciousness, these campaigns attempted to establish the claim that in order to become a good citizen, one had to adopt "Confucian" values. ${ }^{38}$ This conviction fundamentally contradicted Tang's assumption that the course of modernization necessitated a conceptual distinction between the good citizen and the good person.

In light of more recent claims that Confucianism should be viewed as an integral element of the modernization effort in post-Deng China, Tang's cautioning against a misrepresentation of Confucianism has not lost its relevance. To be sure, Tang himself had to cope with the propaganda efforts of

Tang, Renwen jingshen zhi chongjian, pp. $57^{2-573}$ (this passage is taken from Tang's account "Wo duiyu zhexue yu zongjiao zhe jueze").

38 Tu, "Zhonghua wenhua fuxing yundong de shixian yu zhanwang," p. 304 (on campaign measures of the GMD, such as presenting model citizens with official rewards). 
the GMD regime, and not the CCP. Already in the "New Life Movement," the GMD contended that political, economic, and cultural sectors of society could be unified by its one-party rule and claimed that the movement would foster cultural and ideological unity by infusing Confucian values into Chinese society. ${ }^{39}$ Even though the GMD's campaign met with little success, the party, and Chiang Kai-shek personally, continued in the decades that followed to lay claim to a "traditional culture," which they identified with "Confucianism" and declared essential for the advancement of modernization..$^{40}$ After its retreat to Taiwan, the GMD redoubled its efforts to lay claim to "Confucianism" for the nationalist conquest of (Taiwanese) society. Chiang Kai-shek explicitly called Sun Yat-sen's Three Principles of the People an eminent expression of China's age-old Confucian heritage. ${ }^{41}$

In further propaganda efforts instigated in post-war Taiwan, "Confucianism" was said to catalyze the GMD's "revolution" and to serve as a bulwark against "heretical" ideas-i.e. communism. ${ }^{42}$ Chiang Kai-shek took special interest in Wang Yangming's liang zhi thought, interpreting it in highly voluntaristic fashion as a philosophy of action. According to Chiang, this entailed an ethics of conviction and the belief that if one's intentions were truly good and upright, one would certainly succeed in realizing them in practice. ${ }^{43}$ Obviously, the GMD's modernizing efforts to reinvigorate (and reinvent) "traditional culture" and "Confucianism" were opposed to genuinely traditionalist convictions. The GMD advocated a constructivist approach to the past, which was depicted as a reservoir of "progressive" cultural elements that could bolster the GMD's claims to a scientifically and ethically sound modernization program. In contrast, Tang

39 De Bary, Sources of Chinese Tradition. Volume Two. From 1600 Through the Twentieth Century, pp. 339-346.

$40 \quad$ See Chiang Kai-shek's address to the "Society for the Study of Confucius and Mencius" from 1963, in: Zhongguo wenhua xiehui (ed.). Zhonghua wenhua fuxing yundong. Cankao ziliao, pp. 6-7.

41 See Chiang's address from 1961: Ibid., p. 6; in 1963: Ibid., p. 7; and from 1966: Ibid., pp. 4-5; see also Tu, "Zhonghua wenhua fuxing yundong de shixian yu zhanwang," p. 301.

42 See Chiang's address from 1960 on Confucianism as a bulwark against heretic ideas, in: Zhongguo wenhua xiehui (ed.). Zhonghua wenhua fuxing yundong. Cankao ziliao, pp. 5-6; and his address from 1962 on Confucianism as a means in the fight against communism and as a basis for the GMD's revolution; ibid., p. 6.

43 Munro, The Imperial Style of Inquiry in Twentieth-Century China. The Emergence of New Approaches, p. 39. On Chiang Kai-shek's interest in Wang Yangming, see e.g. Chiang, China's Destiny \& Chinese Economic Theory, p. 188; see also Brière, Fifty Years in Chinese Philosophy 1898-1950, pp. 59-60. 
favoured a hermeneutical approach to "Chinese culture" and its Confucian humanistic "main current" which rejected claims to the positivistic identification of allegedly progressive cultural elements. He maintained that interpretations of the past were inevitably shaped by historical contexts-i.e. the process of modernity in which the interpreter was encapsulated - and would never yield guiding principles or values of "objective" validity (see Chap. 4, 11).

Significantly, Tang never joined the chorus of those modernizers who declared that the need for national self-assertion justified violating the institutions of individual rights since it was in the name of a higher interest. Since the 1920s, considerable enthusiasm for Fichte's Reden an die deutsche Nation ${ }^{44}$ had helped to corroborate such a nationalist stance in Chinese intellectual circles. Tang, however, and in spite of his philosophical interest in Fichte, remained aloof from this discussion. His concept of China's national culture, as flawed and outdated as it may appear today, is not in accord with cultural nationalism, let alone the GMD's self-serving conflation of national culture and Confucianism.

44 On the Chinese reception of Fichte; see Kurtz, "Selbstbehauptung mit geliehener Stimme," pp. 221-223. 